\title{
Validity of Adolescents' Report of Maternal Age ${ }^{1}$
}

\author{
Marc A. Zimmerman, ${ }^{2}$ Karen Rowe, Lisa Tuttle, and Alison Bryant \\ University of Michigan
}

Examined the validity of adolescents' reports of their mother's age. Most research on the validity of self-report focuses on personal behaviors such as alcohol and substance use, or response bias due to social desirability. Few studies investigate the validity of adolescents reporting of nonsensitive information. Data from 80 mother-adolescent pairs were collected. The sample included 9th graders from four high school English classes, equal numbers of males and females, and 15\% African Americans. The correlation between mothers' reports and youth' reports of mother's age was .99, and $95 \%$ of the youth were within a year of their mother's correct age. No race or gender differences were found. These results allow researchers to examine adolescent outcomes for youth born to teen mothers without the expense of also collecting data from their mothers. Results also suggest that adolescents' self-reports of other nonsensitive familial data may also be valid.

KEY WORDS: maternal age; adolescent report; validity.

The validity of self-report measures, especially among adolescents, is questioned when research includes sensitive or stigmatizing behavior, and when respondents may be invested in providing what they believe to be favorable or socially desirable answers (Bauman \& Ennett, 1994; Campanelli, Dielman, \& Shope, 1987; Crockett, Schulenberg, \& Petersen, 1987; Davis \& Gergen, 1994). Another concern about youths' self-reports may relate to the validity of information provided about themselves or others. This study

\footnotetext{
${ }^{1}$ This project was funded by the National Institute on Drug Abuse Grant RO1 DA07484 to Marc A. Zimmerman, Department of Health Behavior and Health Education, School of Public Health, University of Michigan, Ann Arbor, Michigan 48109-2029. We thank Mr. Stobie for granting us permission to work in his high school, Lisa Walker for inviting us to work with her classes, and the students for agreeing to participate in the study. We also thank Irwin Sandler whose suggestion led to doing this study.

${ }^{2}$ All correspondence should be sent to Marc A. Zimmerman, Department of Health Behavior and Health Education, School of Public Health, University of Michigan, Ann Arbor, Michigan 48109-2029.
} 
examines the validity of information reported that is not particularly sensitive: adolescents' knowledge of their mother's age. The validity of adolescents' reports of mother's age is a significant issue because it could allow researchers to study effects of teenage parenting on adolescent outcomes without also collecting data from parents. It may also provide evidence that their self-reports of other nonsensitive familial information may be a valid indicator for variables such as family size, birth order, and family structure. Research on outcomes of the adolescent children of teen mothers may be extended in many studies if adolescents' reports of maternal age are valid. Few studies include linked parent-child data that enable assessment of adolescent outcomes for children of teen mothers (e.g., Dubow \& Luster, 1990; East \& Felice, 1990; Furstenberg, Brooks-Gunn, \& Morgan, 1987; Geronimus, Korenman, \& Hillemeier, 1994; Ketterlinus, Henderson, \& Lamb, 1991). Thus, efforts to replicate findings and expand studies of outcomes for children of teen mothers would further our knowledge about the effects of teen parenthood.

\section{METHODS}

\section{Procedure}

Students from four ninth-grade English classes were asked by their teacher to complete a consent form and questionnaire during class time. They were not told the specific purpose of the study. All four classes had the same teacher; however, two classes included accelerated students and two classes consisted of average students. Students placed their questionnaire in an envelope, sealed it, and returned it to the teacher. The teacher put a code number (linked to mother) and indicated the race and gender of each youth on the outside of the envelope. She kept these envelopes, and provided the research team with a list of names and home telephone numbers of students who had agreed to participate.

We then telephoned the students' homes, asked to speak with the student's mother, briefly explained the study, requested a verbal consent to use their own and their child's data and then asked mothers their age and the age of their oldest child. ${ }^{3}$ Students' data for those mothers who consented to participate were collected from the teacher.

\footnotetext{
${ }^{3}$ While the consent procedure protected youth from the use of their data if parental permission was not granted, we did not obtain parental consent prior to students completing the questionnaire (parental permission should typically be obtained prior to questionnaire administration). The data collection procedure was, however, integrated into a classroom exercise about social research, permission was obtained from school officials, and the information obtained was limited and not sensitive.
} 
Ninety-four students participated in the study. Three mothers refused to participate, 4 youth had disconnected telephones, and 7 youth did not live with their mothers. Among the nonparticipant youth, 7 were African American males, 3 were African American females, and 4 were White females. Data from a total of 80 mother-child pairs were obtained for analysis (85\% response rate).

\section{Sample}

The mean age of the adolescents in the final sample $(N=80)$ was $14.2(S D=0.45)$ and the mean age of mothers was $39.3(S D=4.57)$. The sample was predominantly White $(n=61 ; 76 \%)$, with $21 \%(n=17)$ African American and 3\% $(n=2)$ Asian students. Males and females were equally represented (females $=42 ; 53 \%)$.

\section{Measures}

The ninth-graders were asked to answer three written questions: how old are you; how old is your mother; and do you have an older brother or sister-if yes, how old is your oldest brother or sister? Similarly, mothers were asked over the telephone to respond to two questions: what is your age; and what is the age of your oldest child (if not the respondent)?

\section{RESULTS}

Ninety-five percent of the youth $(n=76)$ reported their mother's age within 1 year of their mother. Seventy-one percent $(n=57)$ were exact matches and $24 \%$ either overestimated $(n=8)$ or underestimated $(n=$ 11 ) by 1 year. Only 1 youth was off by 2 years and $3(4 \%)$ were unsure of their mother's age. Table I shows the breakdown of these results by African American versus White, and by gender. Two Asian students were omitted from the table, but their reports of mother's age corresponded with their mother's report.

Bivariate correlations of youths' reports of mother's age and mothers' reports for the total sample was .99. We computed absolute difference scores and used them for group comparisons. We found no differences for sex, $t(75)=0.91$, ns; race (i.e., African American vs. White), $t(73)=0.14$, ns; students whose mothers were teenagers when their first child was born $(n=18)$ versus those mothers who were over 19 years old when their first child was born $(n=62), t(75)=-0.36$, ns; and for youth in accelerated 
Table I. Number of Adolescent Respondent by Race and Gender for Agreement with Mother's Report of $\mathrm{Age}^{a}$

\begin{tabular}{|c|c|c|c|c|c|c|c|c|c|}
\hline \multirow[b]{2}{*}{ Group } & \multirow[b]{2}{*}{$n$} & \multicolumn{2}{|c|}{ Agreement } & \multicolumn{2}{|c|}{ \pm 1 Year } & \multicolumn{2}{|c|}{ \pm 2 Years } & \multicolumn{2}{|c|}{ Unsure } \\
\hline & & $n$ & $\%$ & $n$ & $\%$ & $n$ & $\%$ & $n$ & $\%$ \\
\hline White males & 28 & 17 & 61 & 10 & 36 & - & & 1 & 3 \\
\hline African American males & 10 & 7 & 70 & 3 & 30 & - & & - & \\
\hline White females & 33 & 26 & 79 & 4 & 12 & 1 & 3 & 2 & 6 \\
\hline African American females & 7 & 5 & 71 & 2 & 29 & - & & - & \\
\hline
\end{tabular}

The two Asian students were omitted from the table, but both had agreement with their mother's report of age.

classes $(n=44)$ versus average classes $(n=33), t(75)=0.48$, ns. We then did a chi-square analysis to compare youth who agreed with their mother's reported age $(n=57)$ with those who were off by 1 year or more or did not know $(n=23)$. We found no differences for gender, $\chi^{2}(1)=1.05$, ns; race, $\chi^{2}(1)=0.00$, ns; teen mother, $\chi^{2}(1)=0.01$, ns; or class level, $\chi^{2}(1)$ $=0.02$, ns. Ninety-nine percent of youth with older siblings $(n=37)$, reported the same ages of their siblings as their mother. The correlation between mother-child report of older sibling's age was .996 .

\section{DISCUSSION}

The results of the study suggest that adolescents' reports of their mother's age is a valid measure regardless of gender, race, academic level, and being born to a teen mother. This is a significant finding for researchers interested in the developmental outcomes of the adolescent children of teen mothers because it permits researchers to use this information. The use of adolescents' reports of their mother's age will help increase the samples used to examine effects of teen motherhood on adolescent outcomes when data from mothers are not collected. More research on this topic will help replicate findings across samples and expand the type of outcomes studied. The results of this study also suggest that adolescent's self-report of other nonsensitive familial information may extend beyond mother's age to include other family information. Further research exploring the validity of adolescent report of other nonsensitive information could help improve methodology using self-report data.

\section{REFERENCES}

Bauman, K. E., \& Ennett, S. E. (1994). Tobacco use by black and white adolescents: The validity of self-reports. American Joumal of Public Health, 84, 394-398. 
Campanelli, P. C., Dielman, T. E., \& Shope, J. T. (1987). Validity of adolescents' self reports of alcohol use and misuse using a bogus pipeline procedure. Adolescence, 22, 7-22.

Crockett, L. J., Schulenberg, J. E., \& Petersen, A. C. (1987). Congruence between objective and self-report data in a sample of young adolescents. Joumal of Adolescent Research, 2, 383-392.

Davis, H., \& Gergen, P. J. (1994). The weights and heights of Mexican-American adolescents: The accuracy of self-reports. American Joumal of Public Health, 84, 459-462.

Dubow, E. F., \& Luster, T. (1990). Adjustment of children born to teenage mothers: The contribution of risk and protective factors. Joumal of Marriage and the Family, 52, 393-404.

East, P. L., \& Felice, M. E. (1990). Outcomes and parent-child relationships of former adolescent mothers and their 12-year-old children. Developmental and Behavioral Pediatrics, 11, 175-183.

Furstenberg, F. F., Brooks-Gunn, J., \& Morgan, S. P. (1987). Adolescent mothers and their children in later life. Famity Planning Perspectives, 19, 142-151.

Geronimus, A. T., Korenman, S., \& Hillemeier, M. M. (1994). Does young maternal age adversely affect child development? Evidence from cousin comparisons in the United States. Population and Development Review, 20, 585-609.

Ketterlinus, R. D., Henderson, S., \& Lamb, M. E. (1991). The effects of maternal age-at-birth on children's cognitive development. Journal of Research on Adolescence, 1, 173-188. 